\title{
Mathematics Education in East Asia
}

\author{
Frederick K.S. Leung, Kyungmee Park, Yoshinori Shimizu \\ and Binyan $\mathrm{Xu}$
}

\begin{abstract}
Students in East Asia have been performing extremely well in international studies of mathematics achievements such as TIMSS and PISA. On the other hand, education practices in East Asian countries look different from Western practices, and some practices look very backward and contradictory to what are considered as good practices. Given these intriguing phenomena, this plenary panel aims to discuss different aspects of mathematics education in these East Asian countries, and illustrate its salient features with examples. These aspects include classroom teaching in regular schools and tutorial schools, and pre-service and in-service teacher education and development. The reasons behind the distinctive features of mathematics education in East Asia are then explored, and it is argued that the common Confucian Heritage Culture (CHC) that these countries share best explain these features. This panel presentation is not meant to promote the superior student achievement or good educational practices in East Asia. Rather, it highlights the cultural differences between CHC and Western cultures, rather than the superiority of one over the other. A cultural explanation also means that simple transplant of educational policies and practices from one culture to another will not work. The panel points to the important role culture plays in accounting for educational practices and student achievement.
\end{abstract}

F.K.S. Leung $(\bowtie)$

The University of Hong Kong, Pokfulam, Hong Kong

e-mail: frederickleung@hku.hk

K. Park

Hongik University, Seoul, South Korea

e-mail: kpark@hongik.ac.kr

Y. Shimizu

University of Tsukuba, Tsukuba, Japan

e-mail: yshimizu@human.tsukuba.ac.jp

B. Xu

East China Normal University, Shanghai, China

e-mail: xubinyan650@hotmail.com

(C) The Author(s) 2015 


\section{Introduction}

Students in East Asia have been performing extremely well in international studies of mathematics achievements such as TIMSS and PISA (Beaton et al. 1996; Mullis et al. 1997, 2000, 2004, 2008, 2012; OECD 2001, 2003, 2004, 2010). On the other hand, classroom studies show that mathematics teaching in these countries is rather backward and traditional. International studies on teacher education and development also show that practices in East Asian countries are markedly different from those in "western" countries. Furthermore, comparative studies in teacher knowledge seem to suggest that mathematics teachers in East Asia have more solid understanding of the subject matter as well.

Given these intriguing phenomena, this plenary panel aims to present the current picture of different aspects of mathematics education in these East Asian countries more vividly, and to explore into the reasons behind these distinctive features of mathematics education. In this panel presentation, East Asia is a cultural rather than geographic demarcation. East Asian "countries" refer to systems or economies that are under the influence of the Confucian Heritage Culture, or CHC in short. They include China, Hong Kong, Japan, Korea, Singapore, and Taiwan. The classroom practices, teacher education and development, as well as the educational and sociocultural contexts in these East Asian countries will be discussed and illustrated with examples.

\section{Classroom Teaching in East Asia}

\section{Classroom Teaching in Regular Schools}

There have been many studies about the features of mathematics classroom teaching in East Asia. For example, Zhang et al. (2004) stated that the most coherent and visible principle for mathematics instruction in China is emphasizing the importance of foundations, and the principle of "basic knowledge and basic skills" was explicitly put forward for the teaching of mathematics. Gu et al. (2004) claimed that teaching with variation is a Chinese way of promoting effective mathematics learning. According to Gu et al. (2004) which was based on a series of longitudinal mathematics teaching experiments in China, meaningful learning enables learners to establish a substantial and non-arbitrary connection between their new knowledge and previous knowledge. Classroom activities can be developed to help students establish this kind of connection by experiencing certain dimensions of variation. The theory suggests that two types of variation are helpful for meaningful learning, "conceptual variation" and "procedural variation" (Gu et al. 2004).

A number of comparative studies of classroom teaching in East Asian countries and western countries have been conducted, and among them Leung's study 
provided the most comprehensive interpretation of mathematics teaching in East Asia. In an attempt to search for an East Asian identify in mathematics education, Leung (2001) characterized the salient features of classroom teaching in East Asia and those in the West. He presented six dichotomies of teaching and learning: product (content) versus process; rote learning versus meaningful learning; studying hard versus pleasurable learning; extrinsic versus intrinsic motivation; whole class teaching versus individualized learning; and competence of teachers: subject matter versus pedagogy. Among the six dichotomies, product (content) versus process and whole class teaching versus individualized learning capture best the essence of the differences in mathematics teaching between East Asia and the West.

Two lesson videos were analyzed and discussed in the plenary panel session. As a representative East Asian lesson, an 11th grade Chinese lesson in Shanghai dealing with trigonometric ratio was chosen. In this review lesson, the teacher arranged the mathematics content on trigonometric ratio according to the structure of the knowledge which had already been dealt with in the class, and students accepted and internalized the knowledge structure and reflected on their own understanding. The Chinese lesson shows heavy dependence on teacher's explanation, and the teacher emphasized acquiring mathematics knowledge. Mathematics teaching was analogous to getting the body of knowledge across from the teacher to the students.

For the Western lesson, an 8th grade US lesson in San Diego dealing with linear function was chosen as a representative one. This lesson was characterized as a 'guided development lesson' by the local researchers. The lesson started with some individual activities on exploring the characteristics of functions, and then the teacher invited a student to share his opinion with his classmates. Students were given ample activities and investigations. This lesson seems to support the contemporary Western view that the critical attribute of mathematics is its distinctive way or process of dealing with reality. This process gives rise to a body of knowledge, which is also worthwhile subject matter for study. Since the critical attribute is the process, it is more important to get hold of the process rather than the content arising out of the process.

The Chinese lesson is affirming the importance of the teacher and the subject matter, while student-centered education is the basic tenor in the US lesson. We are not implying that all East Asian countries are on one side of the dichotomies and all western countries are on the other side. In fact, it is a matter of the relative positions of the two cultures on a continuum rather than two incompatible standpoints.

\section{Teaching in Tutorial Schools}

It is well known that there are various types of tutorial schools outside the formal educational system in East Asia. These tutorial schools provide supplementary help in academic subjects both for following-up what is taught in regular schools and for preparing for entrance examinations to the next school levels. The content of the 
Table 1 Expenditure for private tutoring (2012 data taken from Asian Developmental Bank)

\begin{tabular}{l|l}
\hline Country & Total expenditure for private tutoring (billion) \\
\hline Hong Kong & US $\$ 0.255$ \\
\hline Singapore & US $\$ 0.682$ \\
\hline Japan & US $\$ 12.1$ \\
\hline Korea & US $\$ 17.3$
\end{tabular}

courses in those schools can be remedial or accelerated. Tutorial schools range from two or three students meeting in the home of a teacher to hundreds of students in dozens of classes in campuses all over the country.

A huge amount of money is involved in private tutoring. The expenditure for some countries in East Asia is shown in Table 1.

There are both advantages and drawbacks in having such institutions. First, tutorial schools help students to learn, and thus extend their human capital which can in turn contribute to economic development. On the other hand, tutorial schools usually maintain or exacerbate social and economic inequalities. Also, tutorial schools may dominate students' lives and restrict their leisure time in ways that are psychologically and educationally undesirable.

\section{Tutorial Schools or Private Tutoring in Japan}

Table 2 shows the percentages of Japanese students in grades 6 and 9 who attended tutorial $(J u k u)$ schools, including lessons with private tutors (Ministry of Education, Science, Sports, and Culture, 2010). Roughly half of grade 6 students attended some form of outside school education and more than $62 \%$ of grade 9 students attended tutorials. In reality, there are some differences between the urban areas and small cities or rural areas in students' attendance. In urban areas, there are large $J u k u$ schools with a competitive atmosphere mostly attended by students preparing for the university entrance examination. On the other hand, many rural Juku schools for elementary and junior high schools are more informal, and basically aim to provide immediate improvement of school performance. Besides Juku schools

Table 2 Attendance of grade 6 and grade 9 Japanese students in $J u k u$ schools, including lessons with private tutors (National Institute for Educational Policy Research 2010)

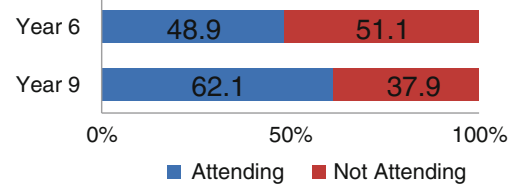


Table 3 Learning in $J u k u$ schools (National Institute for Educational Policy Research 2010)

\begin{tabular}{l|l|l}
\hline Do you study in $J u k u$ schools (including private tutors)? & 6th graders & 9th graders \\
\hline (1) Not attending & 52.1 & 37.9 \\
\hline (2) Learning advanced content or difficult topics & 23.5 & 18.1 \\
\hline (3) Learning the topic taught but not well-understood in schools & 7.5 & 10.0 \\
\hline (4) Both (2) and (3) & 8.5 & 25.9 \\
\hline (5) Others & 8.2 & 7.9 \\
\hline
\end{tabular}

which provide supplementary help in academic subjects, there are enrichment classes on other activities such as swimming, piano, or abacus.

Table 3 shows the various purposes for attending Juku schools. As Table 3 shows, in general learning advanced content or difficult topics is the major purpose of the Japanese students' attendance.

Two Japanese tutorial schools were described in the plenary panel session, one mainly for elementary and junior high school students, and the other mainly for senior high school students. They have different courses and systems. The first tutorial school is a Juku School in Tsukuba City, and the number of students is roughly 400. The school offers "afterschool classes" in weekday evenings for teaching advanced topics, and they provide a bus service to pick up students. The school runs a "Study Camp" every year during the summer vacation, where students stay in a hotel for a few days and learn together.

The other school belongs to an affiliated group of tutorial schools of more than 120 schools all over the country. The school is for university intended senior high school students who prepare for the entrance examination to universities. It provides students with an ICT-enhanced self-learning system that emphasizes a PDCA (Plan-Do-Check-Action) cycle for learning with immediate feedback. All the lectures are delivered through a Local Area Network. Each student comes to the tutorial school after their regular school class and learns with a computer. The progress of their learning is monitored by the teachers at the school and the students have the opportunities for consulting with the teachers periodically to discuss about their choice of intended university and so on.

\section{Tutorial Schools in Korea}

Korea conducts a national survey annually on tutorial schools. Based on the survey done in 2011 with 46,000 students and parents, 50.2\% of elementary and secondary students were participating in mathematics tutorial schools. This rate was the highest among all the subjects.

There are a variety of tutorial schools in Korea according to the achievement levels of the students, their purposes of attending tutorial schools, etc.:

- Repetition of school mathematics content

- Accelerated learning 
- Preparing for mathematics contests or the Mathematics Olympiad

- Preparing for entrance examinations of gifted schools

To reduce the country's addiction to private, after-hours tutoring academies (called hagwons), the authorities have begun enforcing a curfew to stop children from studying in hagwons after 10 p.m. (TIME magazine, 25 Sep 2011).

\section{Teacher Education and Development}

"The success of any plan for improving educational outcomes depends on the teachers who carry it out and thus on the abilities of those attracted to the field and their preparation" (National Research Council 2010, p. 1). In East Asia, respecting teachers and attaching importance to education are an unchanging theme and a traditional virtue (Wang 2012). Teachers play the role of a guide, and instruction is teacher dominated and student involvement is minimal (Leung 2001). On the other hand teachers try to understand their students' learning and want their students to be happy in the future, which means that they need to work hard in school (Ferreras et al. 2010). They bear the responsibility if students do not study hard or work well. One of the Chinese idioms illustrates this typical characteristic of teachers in East Asia: Unpolished jade never shines; To teach without severity is the teacher's laziness (玉不琢, 不成器; 教不严, 师之惰).

In the following section, how teacher preparation and development in East Asia are carried out will be presented.

\section{Pre-service Education: How to Become a Mathematics Teacher in East Asia}

There are diversities in terms of the mechanism for preparing teachers. Some East Asian systems (such as in Korea or in Mainland China) provide an integrated approach where prospective teachers acquire a teacher certificate through a four-year bachelor degree program at a comprehensive university or teacher education university. Some systems (such as Hong Kong or Japan) adopt an end-on approach where prospective teachers complete a bachelor degree and then take a one- or two-year Post Graduate Certificate in Education program. Notwithstanding these differences, some similar characteristics of pre-service teacher training in teachers colleges and normal universities can be summarized as follows ( $\mathrm{Li}$ et al. 2008, p. 70):

- Providing prospective teachers with a solid foundation of mathematical knowledge and advanced mathematical literacy; 
- Emphasizing the review and study of elementary mathematics. It is believed that a profound understanding of elementary mathematics and strong problemsolving abilities in this field are crucial to becoming a qualified mathematics teacher.

The model in each system has its own strengths and weaknesses with regard to acquiring subject matter knowledge, pedagogical knowledge and teaching skills, but they share similar characteristics. The contents of the mathematics teacher preparation programs in some selected institutions are shown in Table 4.

As can be seen in Table 4, the Korean (minimum $30 \%$ ), Chinese (41\%) and Japanese $(33 \%)$ programs emphasize the foundations of mathematics knowledge in terms of its systematic structure, and the demand for logical reasoning. These features could reflect the belief that high quality teaching requires that teachers have a deep knowledge of the subject matter. But, the ways such a belief is reflected in practice depend on the specific contexts found in different countries.

Most of the systems require prospective teachers to obtain a government-issued certificate or license signifying that the candidates have completed the required professional preparation. In many systems, candidates also need to take a teacher employment test, and there is an emphasis on subject matter knowledge in this test in different countries.

Table 4 Outline of Teacher preparation courses for secondary mathematics majors by selected institutions

\begin{tabular}{|c|c|c|c|c|c|}
\hline & $\begin{array}{l}\text { Mathematics (\%) } \\
\text { (required and } \\
\text { elective) (e.g. } \\
\text { Linear algebra, } \\
\text { number theory, } \\
\text { real analysis, } \\
\text { complex analysis, } \\
\text { differential } \\
\text { geometry, } \\
\text { topology, } \\
\text { probability and } \\
\text { statistics) }\end{array}$ & $\begin{array}{l}\text { Mathematics } \\
\text { education (\%) } \\
\text { (e.g. Methodology } \\
\text { of mathematics } \\
\text { education, } \\
\text { curriculum in } \\
\text { mathematics } \\
\text { education, problem } \\
\text { solving and } \\
\text { mathematics } \\
\text { competition) }\end{array}$ & $\begin{array}{l}\text { General } \\
\text { pedagogy (\%) } \\
\text { (e.g. Philosophy } \\
\text { of educational } \\
\text { and history of } \\
\text { education, } \\
\text { curriculum and } \\
\text { evaluation, } \\
\text { educational } \\
\text { method and } \\
\text { technology, } \\
\text { educational } \\
\text { psychology) }\end{array}$ & $\begin{array}{l}\text { Teaching } \\
\text { practicum } \\
(\%)\end{array}$ & $\begin{array}{l}\text { General or other } \\
\text { courses }(\%) \\
\text { (e.g. Foreign } \\
\text { language, health } \\
\text { and sports } \\
\text { subjects) }\end{array}$ \\
\hline China $^{1}$ & 41 & 8 & 10 & 12 & 29 \\
\hline Japan $^{2}$ & 33 & 15 & 16 & 10 & 26 \\
\hline Korea $^{3}$ & 30 & 6 & 13 & 3 & 48 \\
\hline
\end{tabular}




\section{Teacher Employment Test (TET) in Korea}

In Korea, to be employed by national and public schools, a certified teacher must pass the teacher employment test administered by the 16 Metropolitan and Provincial Offices of Education (Ingersoll 2009, p. 58). The competition rates for mathematics in TET differ from one school district to another, but the average competition rate is higher than 10:1, i.e., more than 10 candidates compete for one place.

In the TET administered by the MOE of Korea, the core subjects are 'mathematics', 'mathematics education', and 'general pedagogy'. To examine whether a prospective teacher has successfully developed the practical competency to teach in the classroom, the TET consists of three stages. Table 5 shows the core subjects in the three stages of the examination.

In the first stage, the TET includes 26 questions about mathematics (52\%), 14 questions about mathematics education (28\%), and 40 questions about general pedagogy $(20 \%)$ in the form of multiple choice items. In the second stage, the test

Table 5 The core subjects and three stages of the Korean TET

\begin{tabular}{|c|c|c|c|c|c|}
\hline \multirow[t]{2}{*}{ Area } & \multirow[t]{2}{*}{ Contents } & \multirow{2}{*}{$\begin{array}{l}\text { Relevant } \\
\text { knowledge }\end{array}$} & \multicolumn{3}{|c|}{ Percent } \\
\hline & & & $\begin{array}{l}\text { Stage } \\
1(\%)\end{array}$ & $\begin{array}{l}\text { Stage } \\
2(\%)\end{array}$ & $\begin{array}{l}\text { Stage } \\
3(\%)\end{array}$ \\
\hline \multirow[t]{9}{*}{ Mathematics } & Linear algebra & \multirow{9}{*}{$\begin{array}{l}\text { Content } \\
\text { knowledge }\end{array}$} & \multirow[t]{9}{*}{52} & \multirow[t]{9}{*}{$55-60$} & \multirow[t]{9}{*}{0} \\
\hline & Abstract algebra & & & & \\
\hline & Number theory & & & & \\
\hline & Real analysis & & & & \\
\hline & Complex analysis & & & & \\
\hline & Differential geometry & & & & \\
\hline & Topology & & & & \\
\hline & Probability and statistics & & & & \\
\hline & Discrete mathematics & & & & \\
\hline $\begin{array}{l}\text { Mathematics } \\
\text { education }\end{array}$ & $\begin{array}{l}\text { Mathematics curriculum } \\
\text { and Evaluation, History of } \\
\text { mathematics education, } \\
\text { Theory of instruction in } \\
\text { mathematics, psychology of } \\
\text { teaching mathematics }\end{array}$ & $\begin{array}{l}\text { Pedagogical } \\
\text { content } \\
\text { knowledge }\end{array}$ & 28 & $35-40$ & 60 \\
\hline $\begin{array}{l}\text { General } \\
\text { pedagogy }\end{array}$ & $\begin{array}{l}\text { Philosophy of education } \\
\text { and history of education, } \\
\text { curriculum and evaluation. } \\
\text { educational method and } \\
\text { technology educational } \\
\text { psychology, educational } \\
\text { sociology, educational } \\
\text { administration and } \\
\text { management }\end{array}$ & $\begin{array}{l}\text { General } \\
\text { pedagogical } \\
\text { knowledge }\end{array}$ & 20 & 0 & 40 \\
\hline
\end{tabular}


sets four questions from mathematics (60-65\%) and mathematics education $(35-40 \%)$ in the form of essay items; there are no questions about general pedagogy.

In the final stage, the TET assesses candidates by in-depth interview and microteaching. In the interview, candidates are given a set of questions related to practical issues involving school teaching such as class management and administration issues. In micro-teaching, candidates are asked to develop a teaching plan for a given mathematical topic. They are required to integrate certain instruction features such as using ICT and collaborative learning into the plan. After they set up their plans, they conduct micro-teaching based on the plans for $20 \mathrm{~min}$. The final decision of teacher selection is based on the cumulative scores through the three stages.

\section{Employment Test in Japan}

Due to a decline in the school age population in Japan in recent years, the job opportunities for prospective teachers are limited and only about 30-40\% of graduates of teacher training colleges are able to secure employment in public schools. In principle, mathematics teachers at secondary schools teach only mathematics, whereas teachers at elementary schools teach most subjects. Because of this difference, more courses in pedagogy are required for those intending to teach at the lower grade levels, whereas those intending to teach at the upper grade levels are required to take more mathematics. In addition to the academic course work, teacher-training programs include a practicum (teaching practice). Prospective elementary school teachers are required to spend at least four weeks in a school for teaching practice and those for lower and upper secondary school are required to spend at least two weeks. The practicum is usually preceded and followed by a total of $15-30 \mathrm{~h}$ of related guidance and reflections. The national universities for teacher training have affiliated schools for the purpose of teaching practice.

The board of education of each prefecture gives a teacher certificate to a person who has completed the prescribed basic qualifications and credits at the authorized colleges and universities. The competition rates of Teacher Employment differ among school levels and from one school district (prefecture) to another, but the average competition rate was about 6:1 in 2011 (see Table 6).

Table 6 Applicants, employees, and competition rate in 2011 by school levels (data source Ministry of Education of Japan, as of 1 June 2011)

\begin{tabular}{l|l|l|l|l}
\hline School level & Applicants & $\begin{array}{l}\text { Those who } \\
\text { took the test }\end{array}$ & Employees & $\begin{array}{l}\text { Competition } \\
\text { rate }\end{array}$ \\
\hline Primary school & 63,800 & 57,817 & 12,882 & 4.5 \\
\hline Lower secondary school & 71,212 & 63,125 & 8,068 & 7.8 \\
\hline Upper secondary school & 42,506 & 37,629 & 4,904 & 7.7 \\
\hline
\end{tabular}


For some prefectures, the average competition rate is more than 10 (Iwate 13.6; Nagasaki 13.3), for others, less than 10 (Tokyo 5.7; Toyama 3.7). Each prefecture prepares and conducts an employment test that is conducted at two phases. The first phase is a paper and pencil test (one day in July), and the test subjects consist of general education, mathematics, and mathematics education. The second phase is an interview and micro-teaching (around October).

\section{Teaching Skills Competition for Prospective Mathematics Teachers in China}

In China, the mathematicians in teacher education institutions still value the structure and nature of mathematics, and hope to provide students with a refined and profound mathematics foundation, a broad and concise mathematics background, and further try to help students to master mathematics more easily and properly. And they leave the responsibility of connecting higher mathematics to elementary mathematics and the responsibility of providing high quality mathematics pedagogical knowledge to mathematics educators. Furthermore, enhancing the teaching skills of prospective teachers becomes an important part of the teacher preparation program.

At the end of 1996, the Ministry of Education issued "Suggestions on Teacher Education Reform and Development", emphasizing curriculum reform in order to face the challenges of the 21 st Century. Much importance was attached to the cultivation of scientific thinking and methods, as well as the practical and creative abilities of students, to establish stable bases for teaching practices (Yang et al. 2012, p. 212). Since then different kinds of practice-oriented pre-service programs have been launched and carried out.

Since 2008, the Department of International Cooperation and Exchanges, and the Department of Teacher Education of the Ministry of Education in China, together with Toshiba Company, have been organizing annual competitions on "practice in innovative teaching skills". Students from normal universities/colleges can participate in this competition, but they should first win the local competitions organized by their universities. Only a few students have the honor to take part in the national competition. This competition includes three parts: a lesson plan (jiao an) is designed, the candidates teach a lesson (mo ni ke), and after that they should explain the didactical concepts of their lesson (shuo ke). Through such competitions, most prospective teachers engage in being trained in teaching skills. Many universities/colleges invite excellent school mathematics teachers to tutor the prospective teachers for these competitions (Fu and Han 2010).

\section{In-service Teacher Education and Development}

The success of an education system depends on the appropriate preparation and continuous development of highly qualified teachers. It is widely recognized in East 
Asian education communities that learning to teach in the classroom is a life-long process for teachers. As pointed out above, for becoming a mathematics teacher in this region, it is necessary to acquire a teacher certificate for a particular type of schools by completing credits in teacher training courses offered by universities and colleges. Besides these formal systems of teacher preparation, there are other important aspects in the process of mathematics teacher education in East Asia (Leung and Li 2010; Li and Shimizu 2009). In this section, some characteristics of in-service mathematics teacher education and development in East Asia are described.

Stigler and Hiebert (1999) suggested that it is important to examine and learn the ways employed to improve the quality of mathematics classroom instruction in high-achieving education systems in East Asia. A good example is lesson study, which is now familiar to educators around the world. Lesson study is an important practice utilized in Japan to improve the quality of mathematics instruction and to develop teaching competence by promoting collaboration among teachers (Fernandez and Yoshida 2004). There are many other approaches developed and used in the pursuit of excellence in teacher development in different education systems in East Asia. For example, the model of exemplary lesson development is developed and used in mainland China (Huang and Bao 2006). Instructional contests are organized to identify and promote excellent mathematics instruction in several educational systems (e.g., Li and Li 2009; Lin and Li 2009). Master teachers are also an important part of the teaching culture in some education systems in East Asia, and play an important role in nurturing that culture (Li et al. 2008). Some examples of these approaches are provided below.

\section{Lesson Study in Japan}

Lesson study, originated in Japan, is a common element in approaches to professional developments whereby a group of teachers collaborate to study the subject matter, instruction, and how students think and understand in the classroom. The original term for lesson study, jugyo kenkyu in Japanese, literally means the study of lesson. The origin of lesson study can be traced back to late $1890 \mathrm{~s}$, when teachers at elementary schools affiliated to the normal schools started to study lessons by observing and examining them critically (Inagaki 1995). Groups of teachers started to have study meetings on newly proposed teaching methods. The original way of observing and examining lessons has spread nationwide with some major refinements and improvements. The activities of lesson study include planning and implementing the "research lesson" as the core of the whole activity, followed by post-lesson discussion and reflection by participants. A lesson plan plays the key role as a medium for the teachers to share and discuss the ideas to be examined through the process of lesson study.

Lesson study takes place in various contexts (Shimizu 2002). Pre-service teacher-training programs at universities and colleges, for example, include lesson study as a crucial and challenging part in the final week of student teaching practice. 
In-service teachers also have opportunities to participate in lesson study. It may be held within their schools, outside their schools but in the same school district, city or prefecture, and even at the national level. Teachers at university-affiliated schools that have a mission to develop a new approach to teaching often open their lesson study for demonstrating an approach or new teaching materials they developed.

Lesson study is a problem solving process whereby a group of teachers work on a problem related to a certain theme. The theme can be related to examining the ways for teaching a new content or for using new teaching materials in relation to the revision of the national curriculum guidelines or to assessing students' learning of a certain difficult topic in mathematics such as common fractions or ratio. The first step of lesson study is defining the problem. In some cases, teachers themselves pose a problem to be solved, such as how to introduce the concept of common fractions, or what is an effective way to motivate students to learn mathematics. Second, planning lesson follows after the problem is defined. A group of teachers collaboratively develop a lesson plan. A lesson plan typically includes analysis of the task to be presented and of the mathematical connections both between the current topic and previous topics (and forthcoming ones in some cases) and within the topic, anticipation of students' approaches to the task, and planning of instructional activities based on them. The third step is a research lesson in which a teacher teaches the planned lesson with observation by colleagues. In most cases, a detailed record of teacher and student utterances is taken by the observers for discussion in a post-lesson meeting. Evaluation of the lesson in the post-lesson meeting focuses on issues such as the role of the implemented tasks, students' responses to the tasks, appropriateness of the teacher's questioning, and so on. Based on the evaluation of the lesson, a revised lesson plan is developed, and the lesson is taught again in another class. These entire process forms a cycle of lesson study.

In lesson study, an outside expert is often invited as an advisor who facilitates and makes comments on the improvement of the lesson in the post-lesson discussion (Fernandez and Yoshida 2004). The expert may be an experienced teacher, a supervisor, a principal of a different school, or a professor from a nearby university. In some cases, the expert is not only invited as a commentator in the discussion on site, the group of teachers may meet with him/her several times prior to conducting the research lesson to discuss issues such as reshaping the objective of the lesson, clarifying the role of the task to be posed in the classroom, anticipating students' responses to the task, and so on. In this context, the outside expert can be a collaborator who shares the responsibility for the quality of the lesson with the teachers, and not just an authority who directs the team of teachers.

After researchers in the U.S. introduced lesson study to the mathematics education community during the late 1990s, the term "lesson study" spread among researchers and educators in the U.S. and later around the world (Lewis 2002). One of the most influential books that discusses about lesson study is The Teaching Gap (Stigler and Hiebert 1999). Since then, school teachers in different countries have been trying to implement lesson study in their own education systems. A central question in the "adoption" of the lesson study approach in other places has been raised from the perspective of teaching as a cultural activity. 
In the Japanese education system, improvement of teaching and learning through lesson study over a long period of time can take place within a context in which clear learning goals for students are shared among teachers in relation to the national curriculum standards as well as the voluntary hard efforts of the teachers with the support of the administrators. There are challenges to be resolved in practice and research possibilities to be explored in each context.

\section{Teaching Research Groups and Mentorship in China}

In the Chinese mainland, almost all mathematics teachers are involved in teaching research activities from the first day of their service, in order to obtain practical knowledge and achieve in-service professional development. This is guaranteed by the policy of "the four-level teaching research network comprising about 100,000 officers" (Yang et al. 2012, p. 216). These officers play an important role in China's education system in managing and guiding school-based teaching research activities on the one hand, and bridging the gap between teaching theories and practice on the other.

The basic units of teaching research network activities are teaching research groups and a mentoring system. They cater to the practical needs and professional development of in-service teachers.

\section{Teaching Research Groups in China}

Chinese teachers have a tradition of discussing and reviewing each other's lessons, and gradually it has become a unique culture of opening up one's classroom and discussing one's teaching with others. All the schools in China have teaching research groups, and teachers observing and discussing each other's lessons is commonly guaranteed by the teaching research system. There is more than 50 years' history since a school-based teaching research system was set up in China. In Secondary School Teaching Research Group Rulebook (draft) issued by MOE in 1957, the study function of the teaching research group was emphasized: "A Teaching Research Group is an organization to research teaching. It is not an administrative department. Its task is to organize teachers to do teaching research in order to improve the quality of education, and not to deal with administrative affairs" (Ministry of Education 1957).

Facing challenges of curriculum reform since the 21st Century, the school-based teaching research system is experiencing changes. The changes result not only from changes in the way of teaching and the way of research, but also from changes in the way of learning and the way of experiencing for teachers. The current essential activities of teaching research groups include:

- Action research on classroom teaching to improve effectiveness, whereby several practical research methods are developed, such as analyzing crucial 
teaching events (Yang 2009), classroom observation (Huang and Zhang 2011), and so on.

- Development of a distinctive teaching research culture to build up a teacher community through promoting helping each other and inquiring cooperatively (Yao 2010), or to construct a learning environment to promote teachers' professional development in teaching practice through the learning of teaching theories and the analysis of classroom teaching case studies ( $\mathrm{Gu}$ and Wang 2003).

- Discussion of mathematics contents and corresponding teaching methods to deepen understand and to modify teaching plans [even though this is one of the typical activities, it is facing new challenge because of students' development (Wang 2011)].

\section{Mentoring for Mathematics Teaching in China}

Chinese schools have a tradition of arranging for an experienced teacher to be the mentor for a young teacher when the later just begins the teaching career. In this mentoring system, sometimes a new teacher has two mentors: one provides instructions on teaching and another provides guidance on tutoring students. The experienced teacher (mentor) should undertake the responsibility to discuss teaching methods, teaching contents and students' learning styles, etc., with the novice teacher supervised by him/her. The new teacher is expected to observe the mentor's lessons frequently and learn from him/her enthusiastically and humbly. The school encourages new teachers to conduct open lessons regularly and to participate in teaching contests (Yang et al. 2012). The mentor should try to do coteaching and hold lesson discussion meetings with the mentee, and to suggest alternative teaching practices and ideas (Mao and Yue 2011). In some schools, a ceremony is even held to honor mentors of new teachers and to award them with mentoring certificates.

\section{Mathematics Festival in Korea}

The Ministry of Education in Korea provides compulsory in-service teacher training programs, which Korean teachers should take when they are in the 4th or 5th year of teaching. However many teachers are not satisfied with this teacher training program because it is not very relevant to their classroom teaching. Thus mathematics teacher organizations set up their own teacher training program called 'mathematics festival', and this program has been very successful. Mathematics teachers pay the participation fees from their own pocket.

Mathematics festival is a four-day program, and it consists of a variety of lectures and workshops. The lectures mostly combine theory with its application to classroom teaching. Workshops deal with practical teaching ideas including 
teaching/learning material, manipulatives, teaching tips, etc. Here are examples of lectures and workshops in the 2012 mathematics festival held in January.

- How to teach circumcenter in grade 8

- Harmonics of saxophone from the perspective of mathematics

- Interdisciplinary approach: STEAM (Science, Technology, Engineering, Art, and Mathematics)

- Mathematics magic

- Geogebra, GSP 5.0, Cabri 3D

- Lecture about millennium problems

- Lecture about pentomino with participants' hands-on experience

- Lecture about real world situation (height of shoes)

- Lecture about mathematics and music with musical performance

- Computer session with Geogebra

- Computer session with Cabri 3D

- Hands-on experience to make a traditional 3-dim figure

- Zonodom.

\section{Discussion}

As mentioned earlier, this presentation is not meant to show that all East Asian countries are on one side of the extreme and all Western countries are on the other side. But the presentations above do show that there are distinctive features in the classroom teaching and teacher education and development in East Asian countries which are markedly different from the corresponding practices in Western countries. What are the causes of these differences?

\section{Confucian Heritage Culture}

There are obviously factors at the personal and institutional levels that have caused the differences. But explanation won't be complete without resorting to factors at the socio-cultural levels. China, Korea, Japan share a common culture, the Confucian Heritage Culture (CHC) (Biggs 1996a). A major characteristic of CHC is the social orientation of its people, in contrast to individual orientation typically found in Western societies. Social Orientation is a "tendency to act in accordance with external expectations or social norms, rather than with internal wishes or personal integrity" (Yang 1981, p. 161). It emphasizes integration and harmony, in contrast to independence and individualism in Western cultures (Taylor 1987, p. 235). People in CHC treasure the community, much more so than the individual. Related characteristics of $\mathrm{CHC}$ include compliance, obedience, respect for superiors, and filial piety (孝). 
Another more relevant characteristic in the Confucian culture is its emphasis on education, and $\mathrm{CHC}$ parents are known to attach great importance to the education and achievement of their children. This rests upon the Confucian presumption that everyone is educable [differences in intelligence... do not inhibit one's educability (Lee 1996, pp. 28-29)] and perfectible ["sagehood is a state that any man can achieve by cumulative effort" (Chai 1965)]. This in turn motivates CHC learners to exercise their effort and will power in their study.

On CHC's emphasis on the community, of course it is the individual who learns, so effective teaching must address the needs of the individual. But too much stress on the individual may exaggerate and aggravate the individual differences that already exist. Also, human beings are social beings, and learning almost always takes place in a social context. Western societies may have gone too far in their attempt to care for the individual, and an optimal emphasis on the individual's role in the community may provide important incentives to learn.

\section{Characteristics of CHC Related to Mathematics Learning}

\section{Examination Culture}

China is the first country in the world where a national examination system was instituted (Sui Dynasty, A.D. 600). Examinations have always been the route for upward social mobility, and there is a great trust in examination as a fair method of differentiating between the able and the less able. Examination has acquired the status of something of value in itself and becomes an important incentive for studying.

\section{Belief in Effort}

In CHC, studying is considered a hardship: one should persevere in order to succeed, and is not supposed to "enjoy" the studying. "Asian parents teach their children early that the route to success lies in hard work" (Stevenson 1987), and this is consistent with the old Chinese saying that "Diligence compensates for stupidity" (以勤补拙). There is a much stronger attribution of success and failure to internal and controllable factors (effort) rather than incontrollable ones (innate ability). This is consistent with the strong belief in effort (or Gambaru, which means pushing on, persisting, not giving up) in Japan. Japanese teachers invariably tell parents that "it would be good if the child would just gambaru a little more" (White 1987, p. 30).

The Japanese also emphasize on self-discipline (Kuro). The idea of self-discipline in Japan is slightly different from that in the West. One should do one's best and keep on struggling, even when being unsuccessful in the end. But this is not a pointless sacrifice. In Japan pushing on, persisting and not giving up are in themselves considered important. The way something is done is more important than the accomplishment in the end. 


\section{Stress on Memorization and Practice}

\section{Liu (1986) observed the following beliefs in CHC:}

If the purpose is to acquire the knowledge contained in an article, then the best strategy is to memorize the article. ... If the purpose is to acquire any new cognitive skill, then the best strategy is to practice repeatedly (Liu 1986, pp. 80-82).

This however does not imply rote learning or rule out creativity. As Biggs observed, "the Chinese believe in skill development first, which typically involves repetitive, as opposed to rote learning, after which there is something to be creative with” (Biggs 1996a, p. 55).

\section{Stress on Reflection}

In the Confucian tradition of learning, there is a also strong emphasis on reflection, as the saying "Seeking knowledge without thinking is labour lost; thinking without seeking knowledge is perilous” (学而不思则周, 思而不学则殆) shows. A true Confucian scholar is one who dedicates himself to studying or seeking knowledge through a lot of practice and memorization. But he also constantly reflects upon what he is practicing and memorizing until he fully grasps the knowledge.

\section{Discussion}

Students should enjoy their studies, but they should be taught to rediscover the satisfaction which comes only after hard work. Practice, examination and memorization, when done properly, may each have a place in education. Practice and memorization should not be equated with rote learning, and examination is not a necessary evil. If conducted properly, it provides a good incentive for studying.

\section{The Chinese Language}

The Japanese and Korean languages are strongly influenced by the Chinese language. For example, the Japanese language still uses a lot of Kanji (Chinese characters). There are features of the Chinese language which are favourable to the learning of mathematics. For example, the Chinese language uses classifiers between every cardinal number and the objects being quantified. This "unscramble the confusion that otherwise surrounds conservation of numbers ... explicitness and pragmatic retention of the essential semantic elements in the vocabulary it uses for mathematics" (Brimer and Griffin 1985, p. 23). The regular number system in Chinese also enhances the learning of arithmetic.

As for spoken Chinese, it is a monosyllabic language, where one syllable constitutes one morpheme. In particular, the short pronunciation of the numbers zero to 
ten makes it easy to process. As Hoosain observed, "the shortest average pronunciation duration of a Chinese number is $265 \mathrm{~ms}$, significantly shorter than the corresponding average of $321 \mathrm{~ms}$ in pronouncing a number in English" (Hoosain 1984).

For written Chinese, it is logographic in nature. Chinese words are represented by a large number of different visual symbols known as characters, which are made up of components (radicals), and have an imaginary square as a basic writing unit. Chinese characters put emphasis on the spatial layout of strokes, and the orthography of Chinese is based on the spatial organization of the components of the characters. Lai (2008) pointed out that Chinese characters possess visual properties such as connectivity, closure, linearity and symmetry which are faster and easier to be captured by vision. Studies show that there is a close relationship between the visual-spatial properties of Chinese characters and Chinese people's childhood experience with learning the Chinese orthography. Lai (2008) found that 5 year old Chinese children in Hong Kong, compared to English speaking 5 year olds in Australia, have higher visual perceptual and geometric skills, and higher visualmotor integration skills than motor-reduced visual perceptual skills. Lai used both the motor control theory and the psychogeometric theory of Chinese-character writing to account for the surprising results. It seems that the experience of writing Chinese characters influences one's visual perceptual skills.

\section{Implications}

The superior performance of East Asian students in international studies in mathematics naturally prompts one to ask what can be learned from it, especially when one is facing grave problems in mathematics education in the home country. Some education practices in East Asian countries look different from Western practices, and some practices look very backward and contradictory to what are considered as good practices. Biggs (1996b) introduced the term Chinese Learner's Paradox to describe this contradictory phenomenon. But the phenomenon is a paradox only for someone who does not understand the culture. For someone in the culture, education is so important an endeavour that of course students are expected to do well. Compared to students in some other cultures, CHC students work relatively hard, and it is just natural that they do better in these international studies.

This panel presentation is not meant to promote the high achievement of East Asian students, or good educational practices in East Asia, or the superiority of the CHC. It is meant to highlight the cultural differences between CHC and Western cultures, rather than the superiority of one over the other. Theoretically, it hints at the important role culture could play in accounting for educational practices and student achievement. Practically, it provides references for educators in other cultures on education policies and practices. But if culture does impact upon educational practices and student achievement, a cultural explanation also means 
that simple transplant of educational policies and practices from one culture to another won't work. One can imitate the practices, but cannot transplant the culture, and most practices are effective only in the culture concerned.

\section{Conclusion}

In learning from another country, it is important to take any cultural differences that may exist into consideration, and then determine how much can or cannot be learned from another culture. There is a Chinese saying, "Knowing yourself and knowing others, then you will win every battle” (知已知彼, 百战百胜). In learning from another country or region, we should "know others" - not just the student achievement, not just the educational practices, but also the cultural values behind the practices. One should also know oneself-knowing or reflecting upon one's own cultural values. Then one will win any battle in this war of improving mathematics education in one's own country.

Open Access This chapter is distributed under the terms of the Creative Commons Attribution Noncommercial License, which permits any noncommercial use, distribution, and reproduction in any medium, provided the original author(s) and source are credited.

\section{References}

Beaton, A.E., Mullis, I.V.S., Martin, M.O., Gonzalez, E.J., Kelly, D.L. \& Smith, T.A. (1996). Mathematics Achievement in the Middle School Years. Chestnut Hill, MA: International Study Center, Boston College.

Biggs, J.B. (1996a). Western Misconceptions of the Confucian-Heritage Learning Culture. In D.A. Watkins \& J.B. Biggs (eds.). The Chinese Learner. Hong Kong: Comparative Education Research Centre: 45-67.

Biggs, J.B. (1996b) Approaches to Learning of Asian Students: A multiple paradox. In J. Pandy, D. Sinha \& P.S. Bhawuk (eds.), Asian Contributions to Cross-Cultural Psychology. New Delhi : Sage: $180-199$.

Brimer, A. \& Griffin, P. (1985). Mathematics Achievement in Hong Kong Secondary Schools. Hong Kong: Centre of Asian Studies, University of Hong Kong.

Chai, C. (ed. \& tr.) (1965). The Humanist Way in Ancient China: Essential works of Confucianism. New York: Bantam Books.

Fernandez, C. \& Yoshida, M. (2004). Lesson Study: A Japanese approach to improving mathematics teaching and learning. Mahwah, NJ: Lawrence Erlbaum Associates.

Ferreras, A., Olson, S. \& Sztein, E. (2010). The Teacher Development Continuum in the United States and China: Summary of a Workshop. U.S. National Commission on Mathematics Instruction. Washington, DC: National Academy Press. http://www.nap.edu/catalog/12874. html

Fu, G.S. \& Han, G.F. (2010). A Research on Current Situation and Problems in Normalien Teaching Ability - Teaching ability competition of Normalien as a sample. Contemporary Teacher Education, 3,3: 26-30. 
Gu, L., Huang, R. \& Marton, F. (2004). Teaching with Variation: A Chinese way of promoting effective mathematics learning. In L. Fan, N. Wong, J. Cai, \& S. Li (eds.), How Chinese Learn Mathematics: Perspectives from insiders. River Edge, NJ: World Scientific Publishing Co.: 309-347.

Gu, L.Y. \& Wang, J. (2003). Teachers' Professional Development in Action Education. Curriculum-Textbook-Pedagogy, 1-2: 2-10.

Hoosain, R. (1984). Experiments on Digit Spans in the Chinese and English Languages. In Kao, H.S.R. \& Hoosain, R. (eds.), Psychological Studies of the Chinese Language. Hong Kong: Chinese Language Society of Hong Kong.

Huang, R., \& Bao, J. (2006). Towards a Model for Teacher Professional Development in China: Introducing keli. Journal of Mathematics Teacher Education, 9: 279-298.

Huang, Y.L. \& Zhang, M. (2011). Improve the Effectiveness of Mathematics Teaching - Based on the Action Study of Classroom Observation by Research Group. Journal of Mathematics Education, 20,3: 67-70.

Inagaki, T. (1995). A Historical Research on the Theory of Teaching in Meiji-Era (in Japanese). Tokyo: Hyuuron-Sya.

Ingersoll, R. M. (2009). A Comparative Study of Teacher Preparation and Qualifications in Six Nations. The Consortium for Policy Research in Education (CPRE), 58.

Lai, M.Y. (2008). An Exploratory Study into Chinese and English Speaking Children's Visual Perception. Ph.D. Thesis, The University of Hong Kong.

Lee, W.O. (1996). The Cultural Context for Chinese Learners: Conceptions of Learning in the Confucian Tradition. In D.A. Watkins \& J.B. Biggs, The Chinese Learner. Hong Kong: CERC and ACER: 25-41.

Leung, F.K.S. (2001). In Search of an East Asian Identity in Mathematics Education. Educational Studies in Mathematics, 47,1: 35-51.

Leung, F.K.S. \& Li, Y. (eds.) (2010). Reforms and Issues in School Mathematics in East Asia: Sharing and understanding mathematics education policies and practices. Rotterdam: Sense Publishers.

Lewis, C. (2002). Lesson Study: A handbook of teacher-led instructional change. Philadelphia: Research for Better Schools.

Li, S.Q., Huang, R.J. \& Shin, H. (2008). Discipline Knowledge Preparation for Prospective Secondary Mathematics Teachers: An East Asian Perspective. In: P. Sullivan \& T. Wood (eds). International Handbook of Mathematics Teacher Education: Knowledge and Beliefs in Mathematics Teaching and Teaching Development. Rotterdam: Sense Publishers: 63-86.

Li, Y., \& Li, J. (2009). Mathematics Classroom Instruction Excellence through the Platform of Teaching Contests. ZDM - The International Journal on Mathematics Education, 41,3: 263-277.

Li, Y. \& Shimizu, Y. (2009). Exemplary Mathematics Instruction and Its Development in Selected Education Systems in East Asia. ZDM - The International Journal of Mathematics Education, 41,3: 257-262.

Lin, P. J., \& Li, Y. (2009). Searching for Good Mathematics Instruction at Primary School Level Valued in Taiwan. ZDM - The International Journal on Mathematics Education, 41,3: 363-378.

Liu, I.M. (1986). Chinese Cognition. In Bond, M.N. (ed.), The Psychology of the Chinese People. Hong Kong: Oxford University Press.

Mao, Q.M. \& Yue, K. (2011). Dilemma and Solution of Teacher Learning Based on "Apprenticeship". Research in Educational Development, 22: 58-62.

Ministry of Education (1957). Secondary School Teaching Research Group Rulebook (draft). http://www.ncct.gov.cn/plus/view.php?aid=354 (2013.01.01)

Mullis, I.V.S., Martin, M.O., Beaton, A.E., Gonzalez, E.J., Kelly, D.L. \& Smith, T.A. (1997). Mathematics Achievement in the Primary School Years. Chestnut Hill, MA: International Study Center, Boston College.

Mullis, I.V.S., Martin, M.O., Gonzalez, E.J., Gregory, K.D., Garden, R.A., O'Connor, K.M., Chrostowski, S.J. \& Smith T.A. (2000). TIMSS 1999 International Mathematics Report. Chestnut Hill, MA: International Study Center, Boston College. 
Mullis, I.V.S., Martin, M.O., Gonzalez, E.J., \& Chrostowski, S.J. (2004). TIMSS 2003 International Mathematics Report. Chestnut Hill, MA: TIMSS \& PIRLS International Study Center, Boston College.

Mullis, I.V.S., Martin, M.O. \& Foy, P. (2008). TIMSS 2007 International Mathematics Report. Chestnut Hill, MA: TIMSS \& PIRLS International Study Center, Boston College.

Mullis, I.V.S., Martin, M.O., Foy, P. \& Arora, A. (2012). TIMSS 2011 International Results in Mathematics. Chestnut Hill, MA: TIMSS \& PIRLS International Study Center, Boston College.

National Institute for Educational Policy Research (2010). Results from 2010 National Assessment of Students' Academic Achievements and Learning Environments. Tokyo.

National Research Council (2010). Preparing Teachers: Building Evidence for Sound Policy. Committee on the Study of Teacher Preparation Programs in the United States. Washington, DC: National Academy Press. http://www.nap.edu/catalog/12882.html

Organisation for Economic Co-operation and Development (2001). Knowledge and Skills for Life: First Results from PISA 2000. Paris: OECD Publications.

Organisation for Economic Co-operation and Development (2003). Literacy Skills for the World of Tomorrow - Further Results from PISA 2000. Paris: OECD Publications.

Organisation for Economic Co-operation and Development (2004). Learning for Tomorrow's World - First Results from PISA 2003, OECD.

Organisation for Economic Co-operation and Development (2010). PISA 2009 Results: What Students Know and Can Do, OECD.

Shimizu, Y. (2002). Lesson Study: what, why, and how? In H. Bass, Z.P. Usiskin \& G. Burrill (eds.), Studying Classroom Teaching as a Medium for Professional Development: Proceedings of a U.S.-Japan workshop. Washington DC: National Academy Press: 53-57, 154-156.

Stevenson, H.W. (1987). America's Math Problems. Educational Leadership, 45: 4-10.

Stigler, J.W. \& Hiebert, J. (1999). The Teaching Gap. New York: Free Press.

Taylor, M. J. (1987). Chinese Pupils in Britain. Windsor: NFER-Nelson.

Wang, J.P. (2012). Mathematics Education in China: Tradition and Reality. Singapore: Cengage Learning Asia Pte Ltd.

Wang, X.R. (2011). Inquiring and Reflecting Teaching Research Group Activities in Primary and Secondary Schools - A thematic discussion within mathematics teaching research group in one school. Forum on Education Science, 4: 32-34.

White, M. (1987). The Japanese Education Challenge: A commitment to children. New York: The Free Press.

Yang, K.S. (1981). Social Orientation and Individual Modernity among Chinese Students in Taiwan, Journal of Social Psychology, 113: 159-70.

Yang, Y.D. (2009). Capturing the Crucial Incidents in Teaching Research. People's Education, 1: 48-49.

Yang, Y.D., Li, J., Gao, H. \& Xu, Q.F. (2012). Teacher Education and the Professional Development of Mathematics Teachers. In J.P. Wang, Mathematics Education in China: Tradition and Reality. Singapore: Cengage Learning Asia Pte Ltd.: 205-238.

Yao, H. (2010). Teaching Research Activities - Based on constructing teaching research culture. Primary and Secondary School Management, 9: 35-36.

Zhang, D., Li, S. \& Tang R. (2004). The "Two Basics": Mathematics teaching and learning in mainland China. In L. Fan, N. Wong, J. Cai, \& S. Li (eds.), How Chinese Learn Mathematics: Perspectives from insiders. River Edge, NJ: World Scientific Publishing Co.: 189-207. 